\title{
OCCURRENCE OF LIVER FAILURE IN POST-SURGERY HYPOPITUITARIC PATIENTS
}

\author{
Lo Preiato V., Ribichini D., Baccini M., Pasquali R., Pagotto U.
}

Endocrinology Unit S.Orsola-Malpighi Hospital, Alma Mater University of Bologna, Bologna, Italy \begin{tabular}{l} 
INTRODUCTION \\
\hline Multiple pituitary hormone deficit and \\
hypothalamic obesity are common \\
complications after childhood brain tumors \\
surgery. \\
Despite adequate replacement hormone \\
therapy, obesity develops equally, but liver \\
failure is not usually described.
\end{tabular} INTRODUCTION
Multiple pituitary hormone deficit and
hypothalamic obesity are common
complications after childhood brain tumors
surgery.
Despite adequate replacement hormone
therapy, obesity develops equally, but liver
failure is not usually described. INTRODUCTION
Multiple pituitary hormone deficit and
hypothalamic obesity are common
complications after childhood brain tumors
surgery.
Despite adequate replacement hormone
therapy, obesity develops equally, but liver
failure is not usually described. INTRODUCTION
Multiple pituitary hormone deficit and
hypothalamic obesity are common
complications after childhood brain tumors
surgery.
Despite adequate replacement hormone
therapy, obesity develops equally, but liver
failure is not usually described. INTRODUCTION
Multiple pituitary hormone deficit and
hypothalamic obesity are common
complications after childhood brain tumors
surgery.
Despite adequate replacement hormone
therapy, obesity develops equally, but liver
failure is not usually described. INTRODUCTION
Multiple pituitary hormone deficit and
hypothalamic obesity are common
complications after childhood brain tumors
surgery.
Despite adequate replacement hormone
therapy, obesity develops equally, but liver
failure is not usually described. INTRODUCTION
Multiple pituitary hormone deficit and
hypothalamic obesity are common
complications after childhood brain tumors
surgery.
Despite adequate replacement hormone
therapy, obesity develops equally, but liver
failure is not usually described. INTRODUCTION
Multiple pituitary hormone deficit and
hypothalamic obesity are common
complications after childhood brain tumors
surgery.
Despite adequate replacement hormone
therapy, obesity develops equally, but liver
failure is not usually described.

\section{OBJECTIVES}

We described four cases of cirrhosis, occurred in panhypopituitaric children previously undergone brain tumor surgery.

\begin{tabular}{l} 
OBJECTIVES \\
$\begin{array}{l}\text { We described four cases of cirrhosis, } \\
\text { occurred in panhypopituitaric children } \\
\text { previously undergone brain tumor surgery. }\end{array}$ \\
\hline
\end{tabular}

\section{METHODS}

We studied four subjects referred to our Unit at 19, 23, 23 and 31 years old.

They had undergone surgery for brain tumors involving the peri-hypothalamic area when they were nursing or as youths. One of these patients had a pilocytic astrocytoma, two had a craniopharyngioma, and the last a third ventricle germinoma.

All patients developed panhypopituitarism, but only two had taken adequate hormone replacement therapies since brain damage. In the other two subjects adequate hormonal replacement therapy was started when they came to our observation.

\section{PATIENTS}

Sex

Ty

N

of
Ag

A

$R a$

C

ct

A

$\mathrm{Ac}$ \section{re} \section{\begin{tabular}{|l}
\hline$A$ \\
\hline$A c$ \\
\hline$A c$ \\
\hline$A c$ \\
to \\
\hline$B I$ \\
to \\
\hline
\end{tabular}}

